\section{Notas de um Estudo: reflexões contemporâneas sobre um texto}

Notes from a Study: contemporary remarks on a pioneering text

Ruth Verde Zein*

*Professora e pesquisadora da Universidade Presbiteriana Mackenzie. Doutora (2005) em Teoria, História e Crítica de Arquitetura pela Universidade Federal do Rio Grande do Sul Recebeu o Prêmio CAPES 2006 de Teses da área de Arquitetura e Urbanismo, rzzein@gmail.com

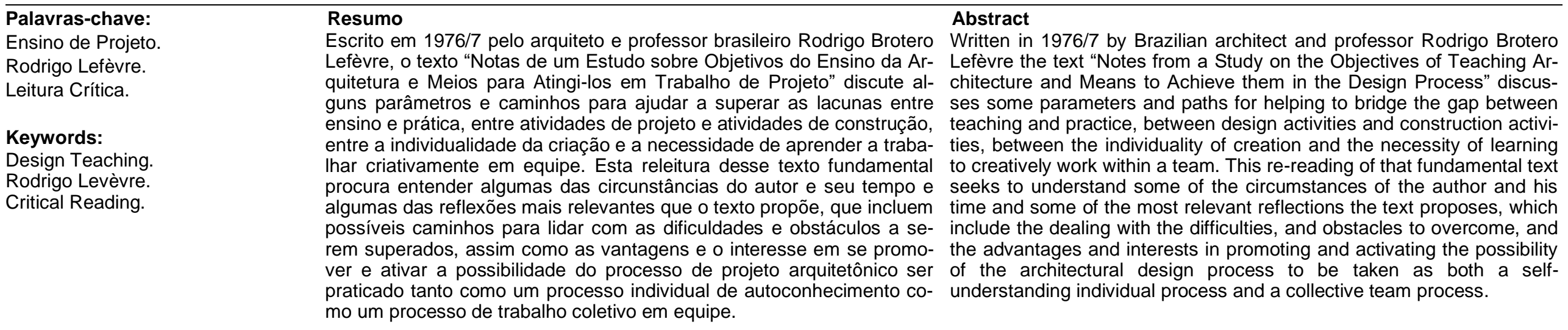

usjt

\section{arq.urb}

número 29 |set- dez de 2020 Recebido: 24/04/2020 Aceito: 06/06/2020

https://doi.org/10.37916/arq.urb.vi29.479 


\section{Introdução}

Uma profissão de ofício se reconhece como atividade atrelada a saberes gradualmente adquiridos pela prática. A arte da construção, ou a arquitetura, tradicionalmente se organizava pelo amálgama das atividades de vários "oficiais", ou profissionais "de ofício", treinados na vida prática a adquirirem certos saberes especializados, transmitidos pelo exemplo, sendo coordenados por um oficial maior (mais experiente) com amplo domínio desses ofícios, por já os estar praticando há algum tempo. Alguns profissionais da arte de construir, ou arquitetura, dispunham de algum saber literário; mas sua erudição usualmente se atinha ao reconhecimento dos precedentes apropriados, cotidianos e/ou notáveis, aplicáveis ao caso, e à sua destreza em emulá-los de forma mais ou menos inovadora e/ou experimental.

É relativamente recente a invenção da ideia do arquiteto não mais como um profissional treinado por um aprendizado prático, mas habilitado pela acumulação de um saber teórico, quando o exercício da arquitetura passa de ser uma profissão "de ofício" a pretender ser uma "profissão liberal". A arquitetura, ou arte de construir, jamais chegará a ser uma atividade de caráter totalmente abstrato. Entretanto, seu ensino e aprendizado muda de foco: passa a ser o domínio da arte de saber projetar em arquitetura. A qualificação desse profissional quase se restringe ao treinamento e domínio individual de uma metalinguagem: a figuração abstrata a priori do que poderá vir a ser, ou não, uma obra de arquitetura. Ao pretender ser reconhecida como produto nascido de uma concepção intelectual, personalizada e individual, a "nova" profissão de arquiteto/a relega a um segundo plano de importância (e frequentemente até esquece) que a execução de uma obra - e mesmo seu projeto - é sempre uma atividade necessariamente envolvendo uma equipe de pessoas, habilitadas em variados saberes, teóricos e práticos. Entretanto, o processo de aprendizagem e "treinamento" de um futuro arquiteto altera-se fundamentalmente, pois passa a enxergar sua meta como sendo a de proporcionar o ambiente e estímulos adequados para que a arquitetura, ou seu projeto, resulte idealmente de uma suposta "criação" pessoal e privativa, operada e, cada caso, por um único e isolado indivíduo.

Mas como as arraigadas práticas milenares da construção seguem existindo e resistindo, inercialmente, às mudanças, a realidade prática cotidiana mais das vezes continua realizando-se indiferentemente às elucubrações intelectualizadas. O ofício de construir "à maneira tradicional" não foi, até agora, de forma alguma eliminado: segue existindo de fato, ainda que precariamente de direito. Por outro lado, como as ideias e pensamentos produzidos pelo pensamento intelectual também progressivamente repercutem, de uma ou outra maneira, na realidade, tampouco nada segue sendo exatamente como antes. O "novo" ofício de "arquiteto liberal" gradualmente se consolida, permeado de contradições, navegando entre quimeras idealizadas e êxitos parciais. E, por isso mesmo, com enorme frequência, jovens recém-formados arquitetos/as se deparam perplexos/as com sua profunda ignorância sobre as coisas práticas da profissão de construir, ou arquitetura. Dão-se conta de estarem pouco ou nada preparados/as para atuarem nesse mundo real, complexo e contraditório, no qual seus saberes e aptidões serão, possivelmente, de pouca valia. E onde, quase sempre, seu status de arquiteto/a não thes vai garantir qualquer primazia; e ainda que tenham a oportunidade de exercer sua profissão de arquiteto/a-projetista será quase sempre como integrante de um grupo ou equipe, que raramente estará sob seu comando.

A possibilidade de sugerir alguns caminhos para ajudar a superar, ainda que parcial e circunstancialmente, esse distanciamento entre o ensino e a prática, entre a atividade de projeto e as atividades da construção, entre a individualidade da criação e a necessidade básica de aprender a trabalhar, criativamente, em equipe parece ter sido a intenção do arquiteto e professor Rodrigo Brotero Lefèvre no seu texto de 1976/7, "Notas de um Estudo sobre Objetivos do Ensino da Arquitetura e Meios para Atingi-los em Trabalho de Projeto". Nesse alentado e complexo artigo, o autor organiza várias reflexões, amplas e pertinentes, de maneira sistemática e concertada, tratando das possibilidades, dificuldades, percalços, escolhos a se superar, e das vantagens e interesses em se promover estímulos adequados para ativar a possibilidade de o "trabalho de projeto" ocorrer enquanto processo de autoconhecimento individual, e através de um trabalho profissional e criativo em equipe. Pode parecer pouco, face ao panorama complicado da vida profissional, ligeiramente descrito acima. Mas não é. Ademais, passados 40 anos de sua publicação, o conteúdo desse artigo permanece bastante atual: os problemas que aponta seguem acontecendo, as propostas que organiza seguem sendo possíveis, viáveis e de interesse. Por isso, parece importante ressaltar, novamente, sua 
pioneira contribuição para o ensino e a prática de projeto de arquitetura, também na contemporaneidade.

\section{Complexidades e contradições pelo caminho}

Publicado originalmente em $1977^{1}$, esse texto (ou alguma versão preliminar dele) foi escrito originalmente em francês, durante a estadia de Lefèvre em Grenoble, França ${ }^{2}$, no ano letivo de 1975/6; e foi provavelmente traduzido ao português (e possivelmente ampliado) pelo próprio autor, após voltar a dar aulas no Brasil, no segundo semestre de 1976. Rodrigo Lefèvre estava temporariamente afastado, entre 1970-1976, das atividades de ensino na FAU-USP, onde atuava como professor desde 1962. Diferentemente da situação de outros professores, que também haviam sido politicamente perseguidos, ele não havia sido oficialmente demitido do corpo docente nos anos em que esteve "compulsoriamente" afastado da universidade. Seu retorno estabeleceu uma situação "de fato", à revelia dos ditames da burocracia e do corpo institucional da universidade, que relutaram em aceitar sua presença. Rodrigo voltava a ser professor, mas somente porque assim o desejava.

Ao retornar já trazia na bagagem a vontade de tratar do assunto do "trabalho de projeto em equipe". A coincidência temporal da elaboração dessas reflexões com o período de afastamento da universidade sugere não ter sido sua atividade anterior como professor o único ou o principal estopim dessa reflexão. Inclusive, arrisco sugerir que sua estada em Grenoble configure mais uma oportunidade, que a causa da escrita desse texto, pois uma parte importante dessas reflexões parece provavelmente ter origem em sua experiência como "arquiteto assalariado" na empresa Hidroservice, onde trabalhou desde 1972 e até o final de sua vida. Em

${ }^{1}$ Recentemente republicado em KOURY, Ana Paula (org), 2019, p.87-140.

${ }^{2}$ Segundo Koury (2019, p.32), "em 1975 [Rodrigo Lefèvre] passa um ano como professor de 2 estúdios interdisciplinares na Unité Pedagogique d'Architecture de Grenoble, França, onde lecionava Sérgio Ferro. A estadia na França rende a Lefèvre um importante ingresso na psicologia através do contato com Françoise du Boisberranger de onde retirou os elementos de que necessitava para transformar o modo de abordar o projeto. Desta estadia decorre a apostila Notes sur le travail de projet dans une école d'architecture, para alunos da Unité pedagogique d'architecture, Grenoble, posteriormente traduzida para os alunos da FAUUSP (Notas de um Estudo Sobre Objetivos do Ensino da Arquitetura e Meios para Atingi-los em Trabalho de Projeto de 1977) e transformada em Disciplina de Extensão Universitária ministrada em colaboração com o Arquiteto Paulo Bicca em 1982." momentos posteriores ${ }^{3}$ Lefèvre vai defender a validade e a importância de sua atuação profissional como assalariado de uma grande empresa, à revelia das críticas de posição "liberal" de seus pares e em sintonia com a realidade já então enfrentada por boa parte de seus alunos. Mas é neste texto que o assunto aparece, pioneiramente, embora de maneira não explícita.

A partir dos anos 1970, importantes mudanças na forma de apropriação e produção capitalista das cidades brasileiras se consolidam, e simultaneamente, alterase significativamente a origem social de uma parte importante do corpo discente das escolas de arquitetura. A partir de finais dos anos 1960, com a pressão para o aumento das vagas nas universidades públicas, bons estudantes, bem formados em escolas primárias e secundárias públicas, então também de boa qualidade, passam a ganhar legitimo e massivo acesso ao ensino superior público; ao mesmo tempo, muitas universidades privadas também abriam seus cursos de arquitetura. Essa camada de jovens estudantes de classe média era, com frequência, a primeira geração de suas famílias a chegar à universidade. Entretanto, mais das vezes não dispunham do capital social necessário para prosperar em escritório próprio, apenas com encomendas de clientes isolados; e tampouco alcançavam ter acesso a encomendas governamentais importantes, ainda comuns nos anos 1970, quando se constituíam como o grosso da clientela habitual dos arquitetos pertencentes às gerações formadas anteriormente a essa expansão do ensino.

Filho de tradicional família burguesa, Rodrigo Brotero Lefèvre escolhe participar de maneira intensa das lutas políticas daquele momento crucial dos anos 1960-70, quando esperanças de mudanças sociais são quebradas pela destruição do regime democrático e instauração da ditadura militar de 1964-85; um engajamento com consequências dramáticas, que resultou na extrema fragilização de sua vida pessoal e profissional. Assim que lhe foi possível, ele volta a exercer sua profissão de arquiteto ${ }^{4}$; em paralelo com algumas encomendas individuais de projetos e assume, como fonte básica de renda, um emprego assalariado e regular em uma grande empresa de engenharia. A qual, por outro lado, Ihe permitia adotar um

3Como no seu depoimento no fórum "Arquitetura e Desenvolvimento Nacional" organizado pelo IAB-SP em 1979 (transcrito em KOURY, 2019, p.157-178), e no texto "O Arquiteto Assalariado" publicado na revista Módulo em 1981 (transcrito em KOURY, 2019, p. 187-194).

${ }^{4}$ De certa forma, nunca deixou de exercer, já que mesmo durante o período em que era preso político seguiu realizando estudos e projetos, viabilizados com o apoio de colaboradores externos. 
regime de trabalho flexível o bastante para que ele continuasse exercendo suas atividades de ensino.

Assim, após um interregno de meia década afastado da universidade, Rodrigo Lefèvre volta a dar aulas na FAU-USP em agosto de 1976. Mas não lhe bastava voltar a ser professor e fazer a diferença pelo contato direto com alguns alunos. Ao voltar também retoma sua prática de escrita, que já vinha prosperando simultaneamente com sua prática profissional e pedagógica. Projetar, escrever, ensinar assim como atuar politicamente - não eram para ele mundos estanques, mas facetas de uma mesma realidade, intensamente vivida em todos os seus aspectos $^{5}$.

Apesar das dificuldades e contradições de seu tempo e condição, Lefèvre se recusa a encarar a realidade então vivenciada como "decepcionante", entendendo ser seu dever ajudar a construir instrumentos para enfrentá-la de maneira consequente e transformadora. Esse parece ser o objetivo, ou melhor, a mensagem de fundo, das "Notas de um Estudo..."; ainda que o autor só declare isso ao final do texto, no último ponto do quarto capítulo:

Existe uma tendência entre nós de considerar todas as nossas ações, todas as nossas atitudes, todos os produtos dos nossos trabalhos como decepcionantes. [...] Isto é, a nossa subjetividade, com a sua alta complexidade, acaba por supor, através de reflexões sobre si mesma, que pode fazer coisas de alto significado, de muita importância - mas na realidade, ao se fazer, ao desenhar, ao escrever, ao fazer uma escultura, ao se relacionar com alguém, o resultado desse fazer nos parece sempre diminuído, sempre menor, sempre decepcionante. [...] De fato, esta decepção não é senão uma atitude que corresponde a uma posição idealista. O que importa, o que é real e o que é modificador é o objeto produzido. É modificador em todos os aspectos, seja na realidade exterior, seja na realidade interior da cabeça de cada um. Um objeto produzido não é nunca decepcionante, não pode ser decepcionante, é, em todas as instâncias, as sínteses concretas do pensamento humano - e contém o pensamento humano. (LEFÈVRE, 1977 In KOURY, 2019, p.138-9)

E para enfrentar e superar essa síndrome da decepção, Lefèvre entende que não basta se apoiar em "coisas palpáveis", pois também as teorias (ou as reflexões teóricas) podem ser, e são, coisas igualmente concretas:

${ }^{5}$ Como no texto de Lefèvre, "Do Pensar, do Fazer..." (in KOURY, 2019, p.141-150), publicado originalmente em 1979.
Mas, se tomarmos uma teoria como um objeto, aí sim poderá haver de novo a possibilidade de destrinchá-la para procurar os elementos da cultura a que ela corresponde, para procurar todos os aspectos diferentes, para procurar mesmo o seu futuro, para procurar o como ela foi produzida, ou para que ela é usada e o que tem sido necessário para conservá-la. Mas isso implica em não tomar uma teoria como verdade absoluta, implica em tomá-la como um meio, necessariamente, entre outros para o desenvolvimento do conhecimento. (LEFÈVRE, 1977 In KOURY, 2019, p.139 - parágrafo final do texto).

À luz dessa compreensão sobre onde o autor parece querer chegar, talvez se possa propor uma breve exegese de algumas das questões que a jornada do texto estabelece. E entender melhor como a questão do "desenvolvimento do conhecimento" é ali tratada não de um modo geral, e sim focada em um assunto restrito e específico: o ensino de projeto de arquitetura. Talvez seja um microcosmos. Mas que contém, ou pode conter, como qualquer coisa e tudo, o mundo.

\section{A estrutura do discurso}

O texto "Notas de um Estudo sobre Objetivos do Ensino de Arquitetura e Meios para Atingi-los em Trabalho de Projeto" se organiza em uma introdução e 4 capítulos. Talvez venha da memória consciente, ou atávica, da formação de base de Rodrigo Lefèvre no ensino jesuítico do Colégio São Luiz, a escolha por adotar uma forma de iniciar e desenvolver o texto dentro de certas regras e medidas da retórica clássica. Por exemplo, na introdução, o autor humildemente se desculpa pelo fato de tratar-se de trabalho incompleto, ou de pouco valor, que considera ser "mais um amontoado de ideias, de apreciações, de suposições do que algo estruturado e desenvolvido para chegar a conclusões comprovadas" (LEFÈVRE, 1977 In KOURY, 2019, p.87). A modéstia é eticamente requerida como atitude a adotar, em oposição à exibição de erudição ou à postura de autoridade soberba. Mas é possível ser exageradamente modesto: o texto é de fato muito bem estruturado, cuidadosa e longamente desenvolvido, vagarosamente se demorando em longas definições de conceitos e ideias, previamente a delas se ocupar e com elas operar. O texto também me recorda certos traços do modo de pensamento de um Spinoza, cuja escrita filosófica deliberadamente adota o encadeamento rítmico das demonstrações matemáticas.

A introdução nos esclarece que a vontade do texto é trazer à tona - ou seja, fazer perceber, de maneira clara e sistemática - o "subjetivismo" dos trabalhos pedagó- 
gicos. Os quais, paradoxalmente, seriam consequência justamente do ato de recusar e/ou de mascarar a subjetividade inerente dos atos humanos, em prol de um "objetivismo" - que tampouco é uma manifestação da vontade de objetividade, mas sua peculiar distorção e/ou dissimulação. Explica também que, para melhor desenvolver essa ideia, irá no primeiro capítulo estabelecer definições (ou conceitos operativos), no segundo alguns postulados (ou teorias), no terceiro uma metodologia de trabalho, e no quarto algumas "anotações", ou considerações sobre como apoiar as propostas apresentadas para sua efetiva aplicação. Finalmente, ainda na introdução, Lefèvre apresenta algumas definições sintéticas dos termos operacionais do texto: subjetividade, subjetivismo, objetividade, objetivismo; em si mesmos, e na sua relação com cada indivíduo.

O capítulo 1 inicia esclarecendo que o que vai importar, ao caso, não são esses termos em si mesmos, mas como esses aspectos se expressam pelas atitudes de um indivíduo, em suas relações com outros indivíduos. Os indivíduos específicos, em exame neste caso, seriam os estudantes de arquitetura. Mas também podem ser, como se deduz pelas possíveis motivações que deram origem a esse texto, os membros de uma equipe de projetos, sejam estes estudantes ou profissionais, nas suas relações entre si.

O primeiro alerta do texto é contra a ideia de que o ensino - e de resto, o projeto possa se fazer a partir do nada. Ao se começar uma tarefa de projeto seria, pois, necessário, evitar a atitude nihilista do "nada sei", e partir da constatação de que, em qualquer que seja o caso, algo já se sabe. Pois será justamente a compreensão desse "algo" que poderá revelar o que se necessita, de fato, buscar saber. Note-se que essa consideração, embora dirigida aos alunos, de fato o é aos professores; os quais são entendidos, no texto, como aqueles cuja tarefa é ajudar e facilitar o aprendizado, e não a simplesmente "outorgar" seu saber (supostamente supremo e inconteste....) a alunos despreparados e/ou em estado prístino de ignorância. Para Lefèvre, "os objetivos de um trabalho didático [...] só podem ter esse conhecimento [do estudante] como ponto de partida. Uma vez o conhecimento anterior negado, os objetivos próprios [de um trabalho didático] não existem ou não estão claros" (LEFĖVRE, 1977 In KOURY, 2019, p.90).

Lefèvre alerta para os possíveis problemas advindos da produção de estudos e projetos permeados por atitudes "subjetivistas" e "objetivistas". Confesso que, sempre que leio ou relembro esse texto, troco mentalmente essas palavras por termos que, a meu ver, podem ser equivalentes: "pseudo-subjetivo" e "pseudoobjetivo". Entendo que há sutis diferenças entre ambos termos; mas aprecio o prefixo "pseudo" porque vem servindo, desde os gregos antigos, para qualificar aquilo que não é, mas pretende ser, aquilo que é mentira ou falsidade - no caso, uma "falsa consciência". Também me sugere a ideia de, ao estarmos estudantes ou professores, raramente somos nós mesmas que ali estamos, mas consciente ou inconscientemente operamos sob o domínio de um "heterônimo", ou uma persona, ou uma personagem.

A boa noticia que Rodrigo nos traz é que, ainda que nossos produtos - desenhos, textos, croquis, maquetes etc. - tenham sido realizados sob a influência de nossas "pseudidades", a força dos fatos nos salva: ainda assim, "um estudo minucioso e sistemático desses resultados pode ajudar a objetivar a subjetividade desse indivíduo" (LEFĖVRE, 1977 In KOURY, 2019, p.91). Essa frase tão singela teve um profundo impacto no meu aprendizado e profissionalização como arquiteta, professora e escritora; de fato, é uma das fontes primordiais de inspiração de dois de meus primeiros textos sobre ensino de arquitetura ${ }^{6}$. A partir das reflexões nascidas da consideração detida e cuidadosa dessa frase compreendi que o papel do/a professor/a, em especial o/a professor/a de projeto, não é o de exarar juízos de gosto, nem o de lançar julgamentos a priori, nem o de fornecer fórmulas mágicas para que os alunos sejam "bem-sucedidos" em suas tarefas - ou qualquer outra atitude professoral explicita ou disfarçadamente autoritária. Mas apenas, e tão somente, analisar com o máximo de conhecimento, rigor e erudição possível os resultados, somente os resultados - e não as ideias; somente os produtos - e não quem os produziu. Por isso, entendo que:

A presença da crítica de arquitetura deve se dar somente quando já iniciada a prática de projeto. Uma crítica de arquitetura minimamente responsável deve negar-se a discutir ideias que ainda não viram a luz do papel - ou do monitor, se for o caso. A primeira atitude dos professores de projeto poderia ser a de só discutir criticamente o projeto do aluno. Parece ser um óbvio ululante, mas não é. (Zein, 2018, p.79-80).

\footnotetext{
${ }^{6}$ Textos escritos em 2001 e 2003 e republicados em Zein (2018, p.68-89 e 90-103).
} 
Mas o texto de Lefèvre vai bem mais além do que essas recomendações gerais. Examina, passo a passo, várias das possíveis e comuns situações que ocorrem durante as interações entre professores e alunos, em ateliês de ensino de projeto, desfolhando minuciosamente cada aspecto, revelando suas diferentes facetas, fazendo sugestões pertinentes, etc. A linguagem adotada pelo autor - não diz "alunos" ou "professores", mas "os que se dedicam a fazer assim, ou assado...", usando com frequência essa forma genérica e indireta (talvez até mais expressiva em francês do que em português) - ocorre, a meu ver, por pura delicadeza. Quem teve o privilégio de conhecer pessoalmente o autor vai recordar sua extrema afabilidade, mesclada a um senso ético de verdade que não Ihe permitia jamais renunciar a dizer e fazer o que fosse necessário. Aliás, esse foi meu primeiro contato com Rodrigo, em agosto ou setembro de 1976: através de sua crítica avassaladora sobre um projeto proposto por uma equipe de colegas estudantes da qual eu fazia parte. Dita com tanta propriedade, firmeza e, simultaneamente, delicadeza, que percebi estar ali, finalmente, um mestre (Zein, 2001).

O segundo capítulo desse texto vai tratar de "postulados" - que a meu ver, também poderiam ser chamados de "teorias", ou ao menos, de um esboço bastante promissor e consequente de uma formulação teórica. Esse trecho também se organiza em 3 partes, ou "problemas", e uma síntese, ou uma aplicação dos conteúdos expostos: a) o problema da demonstração; b) o problema do julgamento; c) o problema da autodemonstração e d) elementos constituintes de uma ação dirigida para um fim. O terceiro capítulo se encerra retomando e consolidando as definições propostas no primeiro capítulo, fundamentando-as de maneira mais cabal e explícita.

Desse segundo capítulo extrairei aqui apenas o que me parece ser uma das frases-chave para a compreensão do foco, intenções e objetivos do texto:

Enfim, o que se pretende procurar é em que se distingue e como podem se desenvolver até a superposição ou a coincidência, duas coisas que são: de um lado, o "desejo" de atingir um fim expresso verbalmente, formado no campo da consciência, presente quase sempre durante toda a ação, mas permanecendo objetivamente inoperante; de outro, uma "disposição real" de atingir um fim, formada no núcleo de evidência, que dá frequentemente resultados sensíveis. (LEFÈVRE, 1977 In KOURY, 2019, p.118)
O que Lefèvre propõe, portanto, é que essa dualidade entre o querer abstrato e o fazer concreto precisaria sintetizar-se em um "fazer querendo", abstrato/concreto, integrado. Infelizmente, não é o que usualmente ocorre em boa parte das atividades de ensino, particularmente de projeto de arquitetura. E ainda mais particularmente no contexto em que Rodrigo escrevia aquelas palavras - os anos 1970 -: tempos duros em que as escolas de arquitetura, de todo o mundo, estavam permeadas por muitos discursos e por uma paradoxal desvalorização e aviltamento das atividades de projeto. Situação que, embora alterada, ainda se faz presente e recorrente, em muitas e variadas situações, ainda hoje, quase meio século depois. Interessante (e triste) como as palavras de Lefèvre soam ainda atuais:

Talvez se esteja atingindo só o grau de consciência dos estudantes sobre os problemas da arquitetura e do urbanismo, não chegando às alterações suficientes de seu núcleo de evidências para que assumam uma "disposição real" de participação na solução desses problemas. Talvez [...] (se) esteja só propiciando aos estudantes uma tomada de consciência de sua necessidade, não chegando a permitir, ou promover, uma alteração das "atitudes" dos estudantes em busca de uma "disposição real" para procurar soluções dos problemas da arquitetura e do urbanismo. (LEFÈVRE, 1977 In KOURY, 2019, p p.118-9)

Naturalmente, muita coisa também mudou, nas décadas que permeiam a fatura desse texto, e o momento contemporâneo. Posso estar sendo parcial, mas a meu ver, se algo mudou, é porque textos como esse existiram, foram lidos, influenciaram, ajudaram a modificar o mundo. Que tenhamos esquecido de onde vieram os incentivos para repensar o ensino e a profissão é apenas um escolho, que tenho certeza, tampouco incomodaria o autor do texto. Não se trata, e não importa muito, quem disse primeiro. Pois a mudança de atitudes, sociais e pedagógicas, nunca pode ser atribuída apenas a um big-bang inicial pois sua efetividade se dá pela acumulação, concentração, repetição e ênfase, por variadas formas, em variadas ocasiões, de alguns conceitos fundamentais. Como aliás Lefèvre o faz, no trecho que destaquei acima: ele diz quase a mesma coisa, duas vezes. A palavra chave, no caso, é "quase". Não é erro, nem redundância: é precisão e estímulo à prontidão.

Postos os conceitos e as ideias, desenvolvidos os postulados e teorias, determinados os problemas, suas causas e desdobramentos, no capítulo 3 o autor vai então, finalmente, propor o que chama de "esboço de uma metodologia". Nova 
repetição do trecho acima: não basta entender os problemas que se apresentam, é preciso ativar uma "disposição ao real" de solucioná-los. Para que algo mude, é preciso projetar uma possibilidade de futuro alternativo ao status quo.

Mas embora o nome dado a essa parte seja "metodologia" não se trata, em absoluto, de um "vade-mécum", ou de uma lista de tarefas, ou de um catálogo ponto a ponto do que deve ser cumprido, ou uma fórmula. Porque o que Rodrigo Lefèvre propõe não é que o espaço exterior mude para conformar-se a uma solução qualquer genial e suprema. Mas que nós, seres em formação e aprendizado, estudantes ou professores, mudemos internamente, a partir da compreensão das nossas próprias verdades.

Em várias frases desse trecho do texto ele inicia por "o que interessa é que..." ou "o que importa é que...". O que interessa é que o aluno (e obviamente, ele também está falando dos colegas professores...) "procure descobrir o que é ele mesmo enquanto produto de sua formação [...] o que é ele mesmo enquanto elemento inserido em um conjunto de relações de outros elementos, procurando a compreensão de sua posição, de suas escolhas nesse conjunto de relações" (LEFĖVRE, 1977 In KOURY, 2019, p.125). Tornar-se consciente de si mesmo seria a única possibilidade real de aprendizado e mudança. Não há como não recordar o "conhece-te a ti mesmo" pitagórico, traduzido pelos gregos a partir dos conhecimentos de anteriores culturas e civilizações; e que, se antes eram esotéricos, agora estão ao alcance de qualquer um. Parece-me evidente que esse trecho deva ser compreendido como uma afirmação de cunho profundamente espiritual. $O$ que não tem nada a ver com qualquer tipo de afiliação religiosa. E, sim, com a profunda atitude ética que embasava e movia as ações e pensamentos do autor desse texto.

Não poderia deixar de citar, também, a frase final desse capítulo, até porque talvez seja uma das mais conhecidas (mas não sei até que ponto, bem compreendidas) desse texto:

O subjetivo será transformado em objetivo, num processo objetivo, num grau de desenvolvimento, quando a representação, ou seja, as imagens de objetos e fenômenos e imagens de relações entre eles, daquele projeto objetivo naquele grau de desenvolvimento, forem não fragmentárias e não incompletas, forem confirme à realidade, estiverem na esfera da evidência e na esfera da consciência ao mesmo tempo. Nesse momento o "desejo" verbalizado corresponde, faz
Notas de um Estudo: reflexões contemporâneas sobre um texto

parte da "disposição real" de realização de uma ação, em busca de um fim. (LEFÈVRE, 1977 In KOURY, 2019, p.129)

Por favor, leia de novo, pausadamente, palavra por palavra. Mesmo se você não entender - e não é fácil, tento entender há anos e com certeza ainda não o consegui plenamente - continue lendo. Pessoalmente, me relembra das aulas sobre Spinoza, ministradas por Marilena Chauí, que tive o privilégio de assistir pouco depois de ler esse texto pela primeira vez. Na geometria filosófica spinoziana (se bem entendi, peço desculpas à professora por minha limitada simplificação e tendência literária às analogias, metonímias e metáforas) a perfeita Liberdade ocorre quando ela se mostra coincidente com a perfeita Necessidade. Ou algo assim.

Mas seria impossível ao ser gentil e modesto que foi Rodrigo Lefèvre terminar um texto assim, de maneira tão triunfal. Talvez seja por isso que se segue, então, o quarto e último capítulo, denominado "notas esparsas", que lhe parece ser necessário adicionar por conta das "condições concretas existentes". Todas as notas (que ele numera de 1 a 11) são extremamente interessantes. Mas como aqui não há pretensão alguma em esgotar o assunto, exerço minha subjetividade e escolho comentar brevemente apenas alguns aspectos que mais me interessam. Eu diria até, que mais me entusiasmaram.

Já fiz exatamente uma seleção assemelhada no começo deste artigo, ao comentar as considerações de Rodrigo sobre a síndrome da decepção, e da teoria como objeto concreto. Mas gostaria de encerrar com um trecho que, de certa forma, valida e autoriza o esforço deste texto. Profeticamente, talvez. Ou são apenas saudades. Trata-se do ponto de número 8 :

Procurar entender as ideias dos outros, tentar sintetizar e depois transmitir aos outros a fim de que eles possam participar das sínteses posteriores, tal deve ser uma atividade a mais a adotar num trabalho de equipe [...] com uma tal forma que os outros possam aderir firmemente às síntese desenvolvendo disposições reais para o cumprimento de tarefas de desenvolvimento daquelas sínteses, de verificação daquelas síntese e de retomadas daquelas sínteses, isto é, com novas sínteses, recomeçar o processo. (LEFÈVRE, 1977 In KOURY, 2019, p p.136-7).

De volta ao futuro. Com a consciência de que tudo o que vem do passado, mas continua significativo, continua em aberto, permanece como desafio a cumprir, segue existindo, estando e atuando, neste presente. 


\section{Referências}

KOURY, Ana Paula. Arquitetura Moderna Brasileira. Uma Crise em Desenvolvimento. Textos de Rodrigo Lefèvre (1963-1981). São Paulo: Edusp Fapesp, 2019.

KOURY, Ana Paula. Grupo Arquitetura Nova. Dissertação de Mestrado. Faculdade de Arquitetura e Urbanismo, Universidade de São Paulo, 1999.

ZEIN, Ruth Verde. Leituras Críticas. São Paulo/Austin: Editora Romano Guerra / Nhamérica, 2018.

ZEIN, Ruth Verde. Rodrigo Brotero Lefèvre, o caminho da Utopia. In O Lugar da Crítica. Ensaios oportunos de arquitetura. Porto Alegre e São Paulo: Centro Universitário Ritter dos Reis e ProEditores, 2001, p.187-190. 